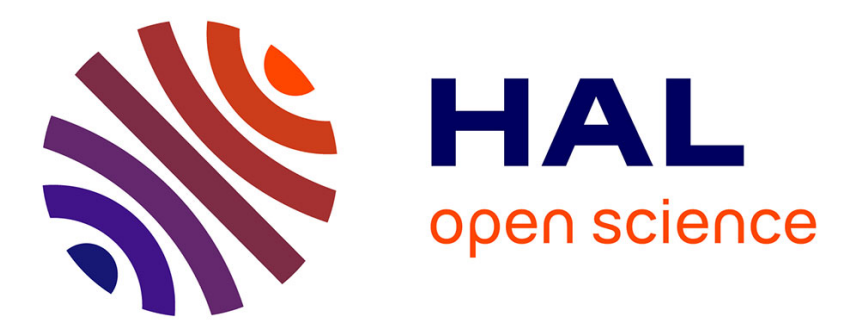

\title{
Supramolecular Induction of Topological Chirality from Nanoscale Helical Silica Scaffolds to Achiral Molecular Chromophores
}

Antoine Scalabre, Ana M Gutiérrez-Vílchez, Ángela Sastre-Santos, Fernando Fernández-Lázaro, Dario M Bassani, Reiko Oda

\section{To cite this version:}

Antoine Scalabre, Ana M Gutiérrez-Vílchez, Ángela Sastre-Santos, Fernando Fernández-Lázaro, Dario M Bassani, et al.. Supramolecular Induction of Topological Chirality from Nanoscale Helical Silica Scaffolds to Achiral Molecular Chromophores. Journal of Physical Chemistry C, 2020, 124 (43), pp.23839 - 23843. 10.1021/acs.jpcc.0c06847 . hal-03042913

\section{HAL Id: hal-03042913 \\ https://hal.science/hal-03042913}

Submitted on 7 Dec 2020

HAL is a multi-disciplinary open access archive for the deposit and dissemination of scientific research documents, whether they are published or not. The documents may come from teaching and research institutions in France or abroad, or from public or private research centers.
L'archive ouverte pluridisciplinaire HAL, est destinée au dépôt et à la diffusion de documents scientifiques de niveau recherche, publiés ou non, émanant des établissements d'enseignement et de recherche français ou étrangers, des laboratoires publics ou privés. 


\title{
Supramolecular Induction of Topological Chirality from Nanoscale Helical Silica Scaffolds to Achiral Molecular Chromophores
}

\author{
Antoine Scalabre, Ana M. Gutiérrez-Vílchez, Ángela Sastre-Santos, Fernando Fernández-Lázaro,* \\ Dario M. Bassani, * and Reiko Oda*
}

Cite This: J. Phys. Chem. C 2020, 124, 23839-23843

Read Online

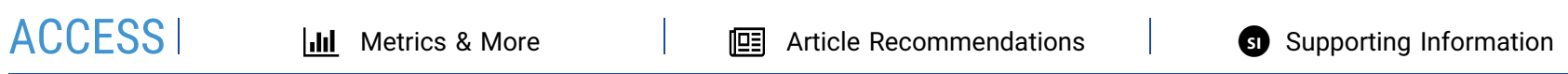
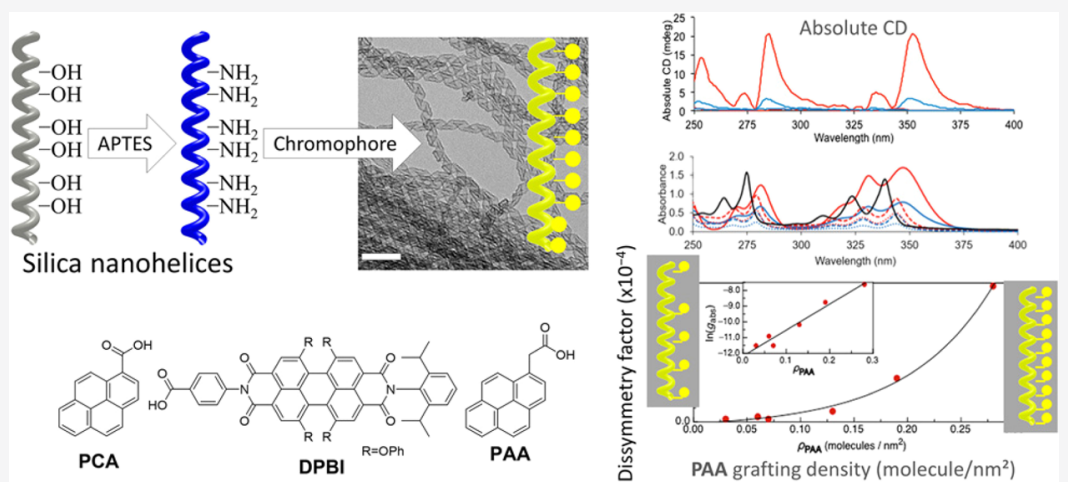

ABSTRACT: Chiral induction from macroscopic objects possessing topological chirality to small molecules is demonstrated using nonchiral organic chromophores based on pyrene and perylene derivatives covalently grafted onto nanometric silica helices. The grafted chromophores are found to display induced chiroptical signals despite the absence of asymmetric atoms. The observed chiral induction is attributed to supramolecular chiral organization of the chromophores on the helical silica surface as evidenced by the variation of the induced circular dichroism signal with increasing surface density of the achiral chromophore. The magnitude of the induced chiroptical signals increases exponentially with the grafting density of the chromophores, suggesting that chiral induction occurs cooperatively.

\section{INTRODUCTION}

Chiral chromophores can exhibit chiroptical properties such as the capability to absorb, and sometimes emit, right- and lefthanded circularly polarized light with different efficiencies. However, the synthesis and purification of enantiomerically pure chromophores with high dissymmetry factors is often challenging. A more general and potentially simpler approach relies on the induction of chirality from accessible, well-defined chiral templates to nonchiral chromophores. To this end, chiral polymers, foldamers, or biomolecules such as DNA or peptides have been employed to organize achiral chromophores through covalent $^{1-3}$ or noncovalent interactions such as H-bonding, ${ }^{4}$ hydrophobic, ${ }^{5}$ or host-guest binding, ${ }^{6,7}$ and have been shown to be effective in inducing chirality from one molecule to another. Other studies showed that chiroptical properties could appear upon chiral aggregation of molecules devoid of optical activity in solution. ${ }^{8-12}$ Tsunega et al. have recently reported the use of cationic polymer-anionic chiral counterion assemblies as templates to prepare silica architectures that can induce chiroptical signals to adsorbed dyes and nanocrystals. $^{13,14}$ Silica with chiral molecular prints has also been used for enantioselective separation/recognition ${ }^{15-17}$ and has been shown to have the ability to induce chiral arrangement to the achiral molecules adsorbed on its surface. ${ }^{18}$ Our previous work has shown that it is possible to induce chiroptical properties to gold nanoparticles or metal complexes organized on the surface of silica nanohelices ${ }^{19,20}$ or using biphenyl-linked polysilesquioxane ${ }^{21}$ through a sol-gel transcription of selfassembled nanohelices from dicationic gemini surfactants. We now show that this method can be generalized for achiral molecular chromophores that are covalently linked to the macroscopic chiral template. Furthermore, the originality of this finding is the obvious induction of chiroptical signals to achiral chromophores using inorganic nanometric chiral platforms of a mesoscopic scale without using the molecular scale imprinting/template, having no chiral molecules or ligands but purely morphological chirality. The induced

Received: July 27, 2020

Revised: September 28, 2020

Published: September 28, 2020 
chiroptical signals are found to be strongly correlated to the density of the grafting, thereby suggesting that the chiral induction from a chiral macroscopic template to a molecular entity is a cooperative supramolecular effect.

\section{RESULTS AND DISCUSSION}

Silica nanohelices were obtained following previously reported protocols. ${ }^{22}$ The surface of the silica helices is functionalized using (3-aminopropyl)triethoxysilane, ${ }^{20}$ which is then reacted with the activated carboxylic acid group of various nonchiral fluorescent chromophores such as pyrene (PCA and PAA) and perylenediimide (DPBI) (Figure 1). ${ }^{23}$
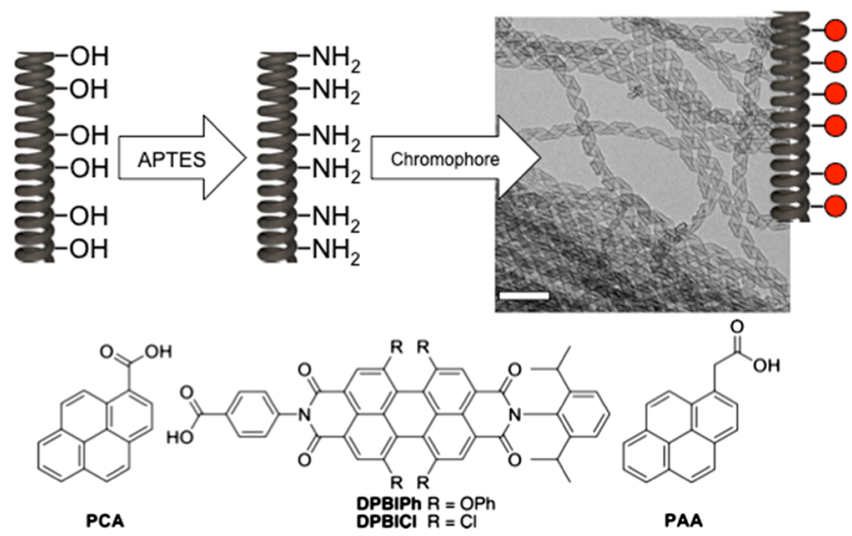

Figure 1. Process for the preparation of silica helices covalently grafted with different organic chromophores and the transmission electron microscopy (TEM) image of a sample of helices grafted with 1-pyreneacetic acid (PAA, Scale bar: $100 \mathrm{~nm}$ ).

Carboxylic acid-functionalized pyrene and perylenediimide chromophores were selected based on their ability to be emissive both in solution and in the solid state in the stacked form (Figure 1)..$^{24-26}$ In view of the limited solubility and strong aggregation propensity of unsubstituted perylenediimides, we chose 1,6,7,12-tetraphenoxy- and 1,6,7,12-tetrachloroperylene derivatives with a bulky solubilizing group in one of the imide positions (DPBIPh and DPBICl, see the Supporting Information for details of synthesis). These molecules are interesting since they cannot be planar because of the steric hindrance of the $\mathrm{R}$ groups in the bay area and therefore adopt twisted conformations that make them chiral and may therefore contribute to the chiroptical properties. ${ }^{27}$ In the case of pyrene, the introduction of a methylene spacer was also investigated to probe the effect of conformational mobility on the intermolecular aggregation on the helix surface. The absorption and emission spectra of all four chromophores shift upon grafting and show induced chiroptical effects.

The CD, absorbance, and fluorescence spectra observed for PCA grafted onto the silica nanohelices are shown in Figure 2. The helical shape of the nanostructures was conserved after the PCA grafting as confirmed by TEM. For PCA, a $3 \mathrm{~nm}$ hypsochromic shift of the absorption maximum at $347 \mathrm{~nm}$ is observed after the grafting. This shift is attributed to excitonic effects because of intermolecular interactions upon packing of the molecules on the surface of the helices (analogous to those resulting from the formation of $H$-aggregates). The surface packing of the chromophores is also consistent with the observation of a broad emission at $475 \mathrm{~nm}$ assigned to excimer emission which is absent in solution (Figure 2). The grafting of the chromophores onto the chiral nanostructures induces supramolecular chirality with a dissymmetry factor around $1 \times$ $10^{-4}$ (calculated at $280 \mathrm{~nm}$ ), with the left- and right-handed helices inducing mirror-image CD signals. This effect confirms the induction of chirality from the helical nanostructure to the molecular chromophore on its surface.

In the case of the DPBI perylene derivatives, a bathochromic shift of the absorption transitions was observed for the $R=$ OPh but not for the $R=\mathrm{Cl}$ derivative as shown in Figure 3 . This might be due to the stacking of the DPBIPh derivatives as observed previously for similar perylene derivatives. ${ }^{28}$ The difference with respect to PCA is attributed to the steric effects of the substituents on the periphery of the perylene moiety, which may induce the molecules to stack in a staircase-like $(J$ type aggregates) arrangement instead of a face-to-face ( $H$-type aggregates) in the case of PCA.

Induction of chiroptical properties is also observed for the DPBI system. However, this induction is smaller than that for PCA, with a dissymmetry factor of $3 \times 10^{-5}$ (at $500 \mathrm{~nm}$ ). This difference also suggests the weaker interchromophore interactions between DPBI with respect to PCA, which is therefore an important factor for the induction of chiroptical properties from the chiral template to the molecular chromophore. Interestingly, the induced $\mathrm{CD}$ shown in Figure 3 bears strong resemblance to the $\mathrm{CD}$ spectra collected on atropoenantiomers of perylenediimide derivatives possessing bulky bay substituents. ${ }^{27}$ This may be an indication that PBI atropoenantiomers may intervene in the induction of chiroptical properties.
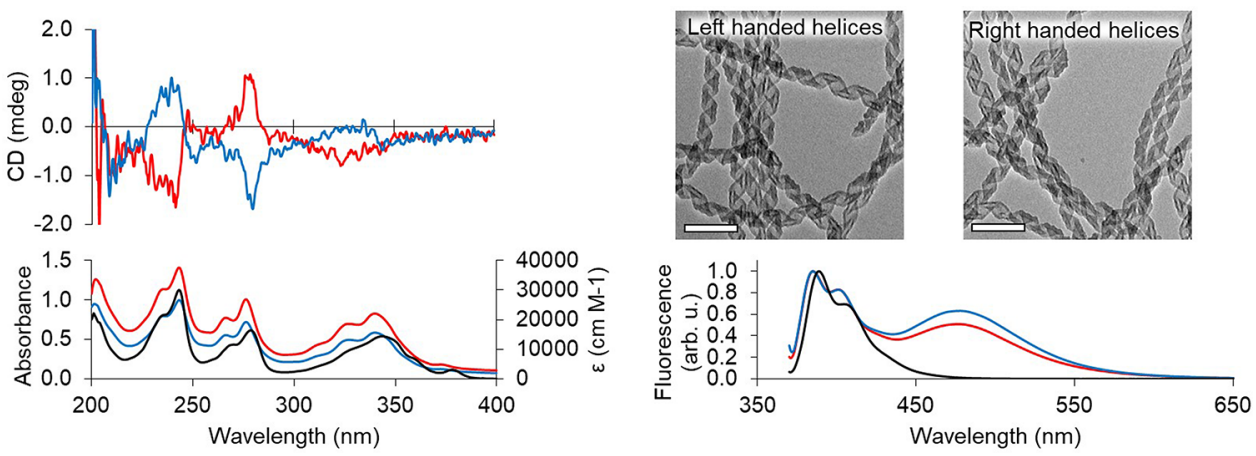

Figure 2. Left: circular dichroism (CD) and absorbance spectroscopy of PCA in ethanol solution (black) and dispersions in ethanol of right- (red) and left-handed (blue) helices grafted by PCA Right: TEM images of the structures (scales bar: $100 \mathrm{~nm}$ ) and fluorescence spectroscopy of PCA solution (black) and right- (red) and left-handed (blue) helices grafted by PCA 

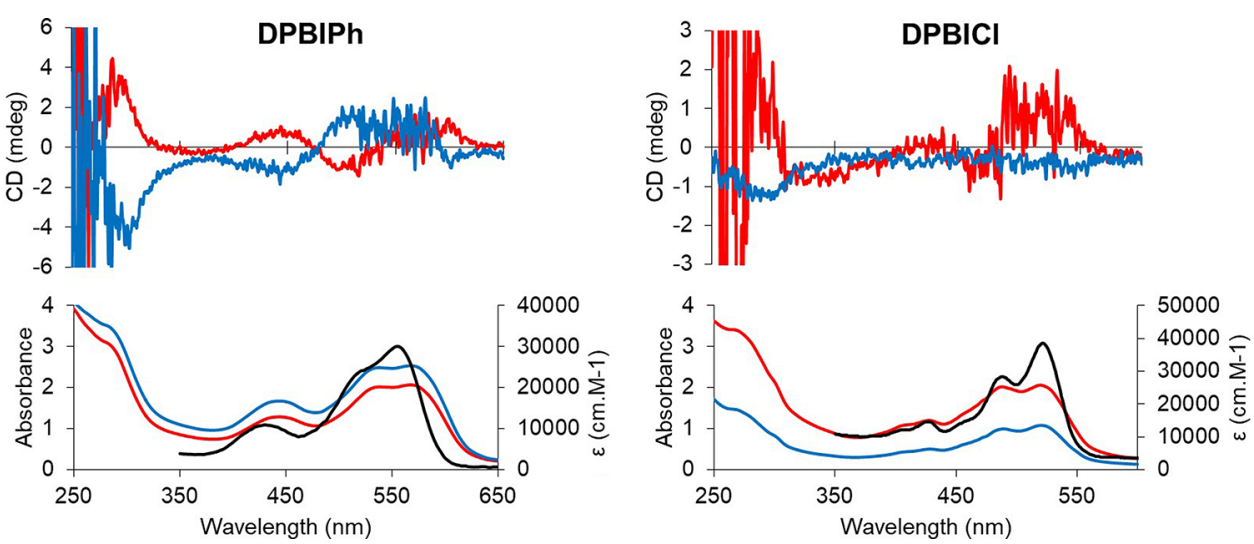

Figure 3. $\mathrm{CD}$ and absorbance spectra in ethanol of DPBIPh (left panels) and DPBICl (right panels) in solution (5 $\mu \mathrm{M}$ in ethanol, black curve) and grafted on left- (blue curves) and right-handed (red curves) helices

To further probe the effect of surface packing and aggregation on the induction of chiroptical properties, we investigated the effect of the conformational mobility of the chromophore by introducing a methylene spacer between the pyrene and the anchoring group (PAA, Figure 1). Upon grafting, PAA exhibits a bathochromic shift of the absorption spectrum as shown in Figure 4. We attribute this to the

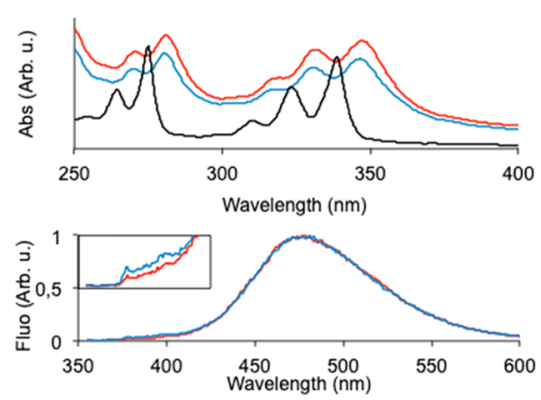

Figure 4. Absorbance and fluorescence spectra in ethanol of PAA in solution (black) and grafted on left- (blue) and right-handed (red) helices

formation of aggregates in which the chromophores are positioned in a staircase arrangement analogously to the DPBI derivative. Similar effects were also documented for biphenylterminated thioalkanes self-assembled on surfaces and assigned to an odd-even chain length affecting the chromophore orientation. ${ }^{29}$ In agreement with a greater conformational mobility of pyrene, grafting of PAA leads to greater intermolecular interactions between grafted chromophores, as evidenced by the much larger proportion of excimer versus locally excited state emission compared to PCA (Figure 2).

We further observed that there is a strong correlation between the dissymmetry factor of the $\mathrm{CD}$ signal and the density of the grafted dyes. Indeed, samples with higher surface grafting density possess larger induced chiroptical signals. To investigate this further, we used absorbance spectroscopy to estimate the overall quantity of dye grafted on the surface of the nanohelices, along with TEM images to estimate the available surface area of the structures in each sample. From this, the average surface density of chromophores $(\rho)$ was calculated and related to the magnitude of the dissymmetry factor $\left(g_{\text {abs }}\right)$. The results are shown in Figure 5 and confirm the initial observations that the magnitude of the induced chiroptical effect is strongly correlated to the density of the
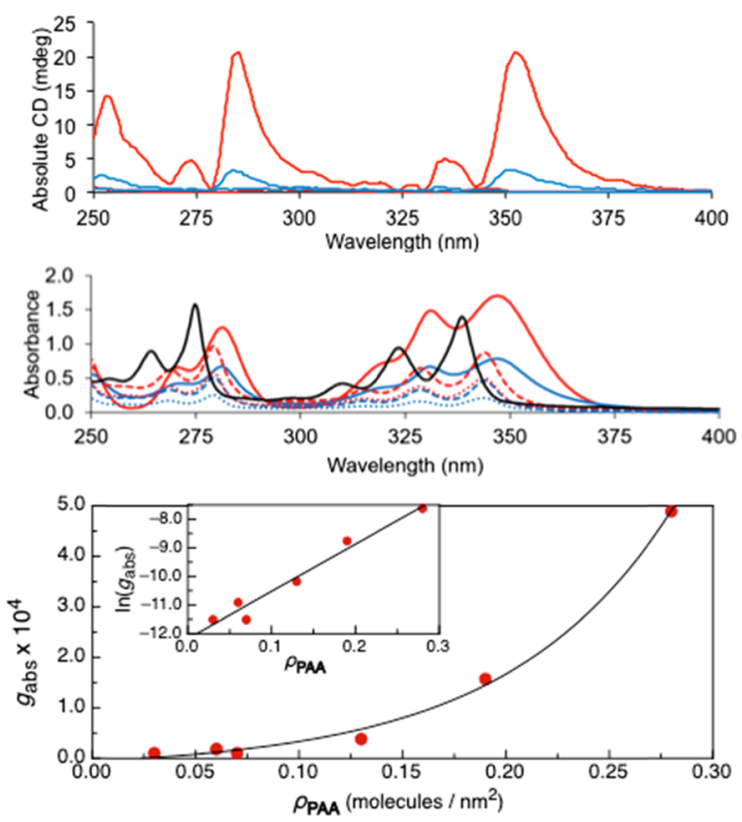

Figure 5. Top: Absolute value of $\mathrm{CD}$ of nanostructures grafted with different densities of PAA (solid red line: $0.28 \mathrm{~nm}^{-2}$, solid blue line: $0.19 \mathrm{~nm}^{-2}$, dashed red line: $0.13 \mathrm{~nm}^{-2}$, and dashed blue line: 0.06 $\mathrm{nm}^{-2}$ ). Middle: Absorbance of PAA in solution (black) and grafted with different densities on the surface of nanostructures (solid red line: $0.28 \mathrm{~nm}^{-2}$, solid blue line: $0.19 \mathrm{~nm}^{-2}$, dashed red line: 0.13 $\mathrm{nm}^{-2}$, dashed blue line: $0.06 \mathrm{~nm}^{-2}$, dotted red line: $0.07 \mathrm{~nm}^{-2}$, and dotted blue line: $0.03 \mathrm{~nm}^{-2}$ ). Bottom: Evolution of the dissymmetry factor (at $358 \mathrm{~nm}$ ) with the density of PAA on the surface of nanostructures. The inset shows the same data in a semilog plot with a linear best-fit to $y=a x+b$ with $a=16.5$ and $b=-12.2\left(r^{2}=0.982\right)$.

grafted chromophores. Below grafting densities of ca. 0.13 PAA $/ \mathrm{nm}^{2}$, (corresponding to a molecular surface area of ca. $6.5 \mathrm{~nm}^{2}$ per PAA molecule), the dissymmetry factor remains below $10^{-4}$. At higher grafting densities, the dissymmetry factor reaches $5 \times 10^{-4}$ at $0.27 \mathrm{PAA} / \mathrm{nm}^{2}$ (i.e., $3.7 \mathrm{~nm}^{2} / \mathbf{P A A}$ ). We note that even though the highest packing density achieved is considerably looser than that expected from a monolayer of tightly packed pyrene chromophores on the surface of the nanohelices, the emission that is collected originates almost exclusively from excimers (Figure 4). Excimer formation requires close contact between the chromophores and the observation of excimer emission is commonly used as a diagnostic for the presence of closely packed chromophores in 
heterogeneous environments or surfaces as its emission is easily distinguished from that of the locally excited state. Additionally, a shift of the absorbance along with a broadening of the peaks for the highly grafted structures (Figure 5) attests to both a change in the environment of the chromophores and electronic interactions between PAA molecules. However, this change is most obvious for values above $0.13 \mathrm{PAA} / \mathrm{nm}^{2}$ below which little or no broadening or CD signal can be observed.

The observed correlation between the grafting density and the optical dissymmetry factors clearly demonstrates the importance of surface aggregation for the induction of chirality between the nanoscale topology and the molecular chromophores. ${ }^{30}$ We interpret this as follows: At low grafting densities, the dyes are too far from each other to form aggregates. In the absence of intermolecular interactions, the chiral curvature of the template's surface (pitch $\sim 65 \mathrm{~nm}$ and diameter $\sim 35 \mathrm{~nm}$ ) is not large enough to impart chiral information to the individual molecules and induce detectable CD signals. At higher grafting density, the surface area per molecule decreases and, eventually, surface-bound aggregates, whose larger size is more sensitive to the chiral curvature of the template, are formed. The template's curvature is expected to slightly offset the anchoring point of vicinal chromophores so as to impart a relative rotation in the direction vectors of their electronic transition dipole moments. This suggests that the induction of chirality to bound dye molecules occurs through the aggregation of dyes and that direct induction of chirality from the curvature of silica surface to an isolated dye molecule is negligible.

\section{CONCLUSIONS}

Our results demonstrate the possibility to induce chiroptical properties onto achiral molecular chromophores using inorganic mesoscopic chiral platforms having no chiral molecules, molecular prints, or ligands but purely morphological chirality at the scale of tens of nanometers (left-or righthanded silica helix). Expectedly, the dissymmetry factors are small compared to molecular systems employing chiral molecules or ligands in which molecular chiral centers are in proximity to the chromophore. ${ }^{31-35}$ Nonetheless, such silica templates provide highly robust chiral nanostructures with good tolerance toward variations in temperature and solvent. The size, pitch, and the handedness of the silica helices can be tailored as needed, making them good potential candidates for the design of robust and tunable chiral surfaces on which achiral dyes can be assembled to obtain chiroptical materials. The correlation between the observed dissymmetry factor and the grafted molecular density suggests that the difference in scale between molecules and nanometric objects is such that individual surface-bound dye molecules grafted on the much larger silica surface do not exhibit chiroptical properties. However, upon forming surface-bound supramolecular aggregates, chiral induction from the template and chiroptical properties are observed. Such assembly-induced chirality induction from the surface of chiral templates may be quite general.

\section{ASSOCIATED CONTENT}

\section{(s) Supporting Information}

The Supporting Information is available free of charge at https://pubs.acs.org/doi/10.1021/acs.jpcc.0c06847.
Experimental details and methods for the synthesis and characterization of achiral perylene chromophores and details of the grafting procedure for the preparation of the hybrid materials (PDF)

\section{AUTHOR INFORMATION}

\section{Corresponding Authors}

Fernando Fernández-Lázaro - Área de Química Orgánica, Instituto de Bioingeniería, Universidad Miguel Hernández de Elche, 03202 Elche, Spain; (1) orcid.org/0000-0002-45986024; Email: fdofdez@umh.es

Dario M. Bassani - Université de Bordeaux, CNRS, Bordeaux INP, ISM, UMR 5255, 33405 Talence, France; @ orcid.org/ 0000-0002-9278-1857; Email: dario.bassani@u-bordeaux.fr

Reiko Oda - Institute of Chemistry \& Biology of Membrane \& Nanoobjects (UMR 5248 CBMN), CNRS - Universite de Bordeaux - Bordeaux INP, 33600 Pessac, France; ○ orcid.org/0000-0003-3273-8635; Email: reiko.oda@ubordeaux.fr

\section{Authors}

Antoine Scalabre - Institute of Chemistry \& Biology of Membrane \& Nanoobjects (UMR 5248 CBMN), CNRS Universite de Bordeaux - Bordeaux INP, 33600 Pessac, France Ana M. Gutiérrez-Vílchez - Área de Química Orgánica, Instituto de Bioingeniería, Universidad Miguel Hernández de Elche, 03202 Elche, Spain

Ángela Sastre-Santos - Área de Química Orgánica, Instituto de Bioingeniería, Universidad Miguel Hernández de Elche, 03202

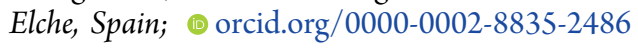

Complete contact information is available at: https://pubs.acs.org/10.1021/acs.jpcc.0c06847

\section{Author Contributions}

The manuscript was written through contributions of all authors. All authors have given approval to the final version of the manuscript.

Notes

The authors declare no competing financial interest.

\section{ACKNOWLEDGMENTS}

This work was supported by the Strategic International Collaborative Research Program between JST in Japan and ANR (ANR-CONACYT-159884) in France, the France-Japan International Associated Laboratory on Chiral Nanostructures for Photonic Applications (LIA-CNPA) and by European Regional Development Fund "A way to make Europe", and the Spanish Ministerio de Ciencia e Innovacion, Agencia Estatal de Investigación (CTQ2016-77039-R and PID2019-109200GBI00 AEI/FEDER, UE).

\section{REFERENCES}

(1) Jiang, Q.; Xu, X.; Yin, P.-A.; Ma, K.; Zhen, Y.; Duan, P.; Peng, Q; Chen, W.-Q.; Ding, B. Circularly Polarized Luminescence of Achiral Cyanine Molecules Assembled on DNA Templates. J. Am. Chem. Soc. 2019, 141, 9490-9494.

(2) Nakamura, M.; Ota, F.; Takada, T.; Akagi, K.; Yamana, K. Circularly polarized luminescence of helically assembled pyrene $\pi$ stacks on RNA and DNA duplexes. Chirality 2018, 30, 602-608.

(3) Zhou, C.; Duan, X.; Liu, N. DNA-Nanotechnology-Enabled Chiral Plasmonics: From Static to Dynamic. Acc. Chem. Res. 2017, 50, 2906-2914. 
(4) Mizutani, T.; Takagi, H.; Hara, O.; Horiguchi, T.; Ogoshi, H. Axial chirality induction in flexible biphenols by hydrogen bonding and steric interactions. Tetrahedron Lett. 1997, 38, 1991-1994.

(5) Goto, T.; Okazaki, Y.; Ueki, M.; Kuwahara, Y.; Takafuji, M.; Oda, R.; Ihara, H. Induction of Strong and Tunable Circularly Polarized Luminescence of Nonchiral, Nonmetal, Low-MolecularWeight Fluorophores Using Chiral Nanotemplates. Angew. Chem., Int. Ed. 2017, 56, 2989-2993.

(6) Allenmark, S. Induced circular dichroism by chiral molecular interaction. Chirality 2003, 15, 409-422.

(7) Kikuchi, Y.; Kobayashi, K.; Aoyama, Y. Molecular recognition. 18. Complexation of chiral glycols, steroidal polyols, and sugars with a multibenzenoid, achiral host as studied by induced circular dichroism spectroscopy: exciton chirality induction in resorcinol-aldehyde cyclotetramer and its use as a supramolecular probe for the assignments of stereochemistry of chiral guests. J. Am. Chem. Soc. 1992, 114, 1351-1358.

(8) Bettini, S.; Syrgiannis, Z.; Ottolini, M.; Bonfrate, V.; Giancane, G.; Valli, L.; Prato, M. Supramolecular Chiral Discrimination of DPhenylalanine Amino Acid Based on a Perylene Bisimide Derivative. Front. Bioeng Biotec. 2020, 8, 1-11.

(9) Imai, Y.; Kawano, K.; Nakano, Y.; Kawaguchi, K.; Harada, T.; Sato, T.; Fujiki, M.; Kuroda, R.; Matsubara, Y. Control of circularly polarized luminescence $(\mathrm{CPL})$ properties by supramolecular complexation. New J. Chem. 2008, 32, 1110-1112.

(10) Kaiser, T. E.; Stepanenko, V.; Würthner, F. Fluorescent JAggregates of Core-Substituted Perylene Bisimides: Studies on Structure-Property Relationship, Nucleation-Elongation Mechanism, and Sergeants-and-Soldiers Principle. J. Am. Chem. Soc. 2009, 131, 6719-6732.

(11) Li, H.; Cheng, J.; Deng, H.; Zhao, E.; Shen, B.; Lam, J. W. Y.; Wong, K. S.; Wu, H.; Li, B. S.; Tang, B. Z. Aggregation-induced chirality, circularly polarized luminescence, and helical self-assembly of a leucine-containing AIE luminogen. J. Mat. Chem. C 2015, 3, 2399-2404.

(12) Stepanenko, V.; Li, X.-Q.; Gershberg, J.; Würthner, F. Evidence for Kinetic Nucleation in Helical Nanofiber Formation Directed by Chiral Solvent for a Perylene Bisimide Organogelator. Chem. - Eur. J. 2013, 19, 4176-4183.

(13) Sugimoto, M.; Liu, X.-L.; Tsunega, S.; Nakajima, E.; Abe, S.; Nakashima, T.; Kawai, T.; Jin, R.-H. Circularly Polarized Luminescence from Inorganic Materials: Encapsulating Guest Lanthanide Oxides in Chiral Silica Hosts. Chem. - Eur. J. 2018, 24, 6519-6524.

(14) Tsunega, S.; Jin, R. H.; Nakashima, T.; Kawai, T. Transfer of Chiral Information from Silica Hosts to Achiral Luminescent Guests: a Simple Approach to Accessing Circularly Polarized Luminescent Systems. ChemPlusChem 2019, 85, 1-626.

(15) Lacasta, S.; Sebastián, V.; Casado, C.; Mayoral, Á.; Romero, P.; Larrea, Á.; Vispe, E.; López-Ram-de-Viu, P.; Uriel, S.; Coronas, J. Chiral Imprinting with Amino Acids of Ordered Mesoporous Silica Exhibiting Enantioselectivity after Calcination. Chem. Mater. 2011, 23, 1280-1287.

(16) Paik, P.; Gedanken, A.; Mastai, Y. Enantioselective Separation Using Chiral Mesoporous Spherical Silica Prepared by Templating of Chiral Block Copolymers. ACS Appl. Mat. Interfaces 2009, 1, 18341842.

(17) Qiu, X.; Hao, J.; Li, J.; Gong, Z.; Li, S.; Cheng, J.; Lin, X.; He, T. Strong multiphoton absorption in chiral $\mathrm{CdSe} / \mathrm{CdS} \mathrm{dot} / \mathrm{rod}$ nanocrystal-doped poly(vinyl alcohol) films. Opt. Lett. 2019, 44, 2256-2259.

(18) Matsukizono, H.; Jin, R.-H. High-Temperature-Resistant Chiral Silica Generated on Chiral Crystalline Templates at Neutral $\mathrm{pH}$ and Ambient Conditions. Angew. Chem., Int. Ed. 2012, 51, 5862-5865.

(19) Attoui, M.; Pouget, E.; Oda, R.; Talaga, D.; Le Bourdon, G.; Buffeteau, T.; Nlate, S. Optically Active Polyoxometalate-Based Silica Nanohelices: Induced Chirality from Inorganic Nanohelices to Achiral POM Clusters. Chem. - Eur. J. 2018, 24, 11344-11353.
(20) Cheng, J.; Le Saux, G.; Gao, J.; Buffeteau, T.; Battie, Y.; Barois, P.; Ponsinet, V.; Delville, M.-H.; Ersen, O.; Pouget, E.; et al. GoldHelix: Gold Nanoparticles Forming 3D Helical Superstructures with Controlled Morphology and Strong Chiroptical Property. ACS Nano 2017, 11, 3806-3818.

(21) Ryu, N.; Kawaguchi, T.; Yanagita, H.; Okazaki, Y.; Buffeteau, T.; Yoshida, K.; Shirosaki, T.; Nagaoka, S.; Takafuji, M.; Ihara, H.; et al. Chirality induction on non-chiral dye-linked polysilsesquioxane in nanohelical structures. Chem. Commun. 2020, 56, 7241-7244.

(22) Okazaki, Y.; Cheng, J.; Dedovets, D.; Kemper, G.; Delville, M.H.; Durrieu, M.-C.; Ihara, H.; Takafuji, M.; Pouget, E.; Oda, R. Chiral Colloids: Homogeneous Suspension of Individualized $\mathrm{SiO}_{2}$ Helical and Twisted Nanoribbons. ACS Nano 2014, 8, 6863-6872.

(23) Lee, S. Y.; Murphy, J. M.; Ukai, A.; Fu, G. C. Nonenzymatic Dynamic Kinetic Resolution of Secondary Alcohols via Enantioselective Acylation: Synthetic and Mechanistic Studies. J. Am. Chem. Soc. 2012, 134, 15149-15153.

(24) Nowak-Król, A.; Shoyama, K.; Stolte, M.; Würthner, F. Naphthalene and perylene diimides - better alternatives to fullerenes for organic electronics? Chem. Commun. 2018, 54, 13763-13772.

(25) Ramírez, M. G.; Pla, S.; Boj, P. G.; Villalvilla, J. M.; Quintana, J. A.; Díaz-García, M. A.; Fernández-Lázaro, F.; Sastre-Santos, Á. 1,7Bay-Substituted Perylenediimide Derivative with Outstanding Laser Performance. Adv. Opt. Mat. 2013, 1, 933-938.

(26) Signoretto, M.; Zink-Lorre, N.; Suarez, I.; Font-Sanchis, E.; Sastre-Santos, Á.; Chirvony, V. S.; Fernández-Lázaro, F.; MartinezPastor, J. P. Efficient optical amplification in a sandwich-type activepassive polymer waveguide containing perylenediimides. ACS Photonics 2017, 4, 114-120.

(27) Osswald, P.; Würthner, F. Effects of Bay Substituents on the Racemization Barriers of Perylene Bisimides: Resolution of AtropoEnantiomers. J. Am. Chem. Soc. 2007, 129, 14319-14326.

(28) Würthner, F.; Kaiser, T. E.; Saha-Möller, C. R. J-Aggregates: From Serendipitous Discovery to Supramolecular Engineering of Functional Dye Materials. Angew. Chem., Int. Ed. 2011, 50, 33763410.

(29) Heister, K.; Rong, H.-T.; Buck, M.; Zharnikov, M.; Grunze, M.; Johansson, L. S. O. Odd-Even Effects at the S-Metal Interface and in the Aromatic Matrix of Biphenyl-Substituted Alkanethiol SelfAssembled Monolayers. J. Phys. Chem. B 2001, 105, 6888-6894.

(30) Richardson, F. S. Selection rules for lanthanide optical activity. Inorg. Chem. 1980, 19, 2806-2812.

(31) Jin, W.; Fukushima, T.; Niki, M.; Kosaka, A.; Ishii, N.; Aida, T. Self-assembled graphitic nanotubes with one-handed helical arrays of a chiral amphiphilic molecular graphene. Proc. Natl. Acad. Sci. U. S. A. 2005, 102, 10801-10806.

(32) Okazaki, Y.; Buffeteau, T.; Siurdyban, E.; Talaga, D.; Ryu, N.; Yagi, R.; Pouget, E.; Takafuji, M.; Ihara, H.; Oda, R. Direct Observation of Siloxane Chirality on Twisted and Helical Nanometric Amorphous Silica. Nano Lett. 2016, 16, 6411-6415.

(33) Wang, F.; Ji, W.; Yang, P.; Feng, C.-L. Inversion of Circularly Polarized Luminescence of Nanofibrous Hydrogels through Coassembly with Achiral Coumarin Derivatives. ACS Nano 2019, 13, 7281-7290.

(34) Wang, Y.; Zhou, D.; Li, H.; Li, R.; Zhong, Y.; Sun, X.; Sun, X. Hydrogen-bonded supercoil self-assembly from achiral molecular components with light-driven supramolecular chirality. J. Mater. Chem. C 2014, 2, 6402-6409.

(35) Yang, D.; Duan, P.; Zhang, L.; Liu, M. Chirality and energy transfer amplified circularly polarized luminescence in composite nanohelix. Nat. Commun. 2017, 8, 15727. 